\title{
O PAPEL DO ASSESSOR DE COMUNICAÇÃO SOCIAL NO GERENCIAMENTO DE CRISE
}

\author{
Klebson Azevedo da Silva ${ }^{1}$
}

\section{RESUMO}

Toda instituição, incluindo-se aquelas da esfera pública, está sujeita a lidar com o momento de crise, e estar preparado para seu enfrentamento é um desafio proposto ao assessor de comunicação no desempenho de sua função e a todos os diretores e gestores da instituição. Entender o que é a crise e o que ela representa para a instituição significa reconhecer a importância de estar preparado para o período adverso atuando preventivamente através de um trabalho forte e integrado com todos os atores do órgão que compõem 0 gabinete ou comitê de crise. A preocupação do assessor de comunicação, inserido no cenário de uma crise, é cuidar dos bens intangíveis, como a imagem e reputação institucional, buscando informações importantes sobre a crise e estabelecendo um canal de comunicação entre a instituição e a sociedade através dos meios de comunicação, cumprindo assim o seu papel. Isso só será alcançado com estratégias bem definidas de abordagem e cuidados nos processos comunicacionais que devem acontecer antes mesmo da instalação efetiva da crise, identificando e reduzindo vulnerabilidades através de reuniões frequentes entre os componentes do gabinete de crise. Sendo assim, é indiscutível que uma instituição que preza pela sua imagem e reputação deve, todos os dias, buscar meios de fortalecer esses bens intangíveis, capacitando seus profissionais e eliminando ou reduzindo os riscos de instalação de uma crise, aprendendo com estudos de casos com os erros de outras instituições ou mesmo com seus próprios erros a fim de que não atinjam novamente a instituição. Diante disso, a área de comunicação, sem dúvida, é uma das áreas mais importantes no gerenciamento de crises, tendo a capacidade de sanar ou mesmo agravar uma crise.

Palavras-chave: Gerenciamento de crise. Assessoria de imprensa. Comunicação. Comunicação pública.

\footnotetext{
${ }^{1}$ Capitão do Corpo de Bombeiros Militar de Pernambuco, Pós-Graduado em Comunicação Pública pela Faculdade Unyleyia. E-mail: klebsoncbmpe@gmail.com
} 


\title{
THE ROLE OF THE SOCIAL COMMUNICATION ADVISER IN CRISIS MANAGEMENT
}

\begin{abstract}
Every institution is subject to dealing with moments of crisis, among them, public institutions. To understand the meaningofcrisisandwhat it representes to the institution, it is necessary to recognize the obligation of being prepared to the moments of adversity and the necessity of acting in a preventive way through a hard way and connected with all the components of the institution who composse the cabinet of crisis. The communication consultant's concern during a crisisis to take care of the institution intangible assetssuch as its image and reputation, seeking for importantin formation about the crisis and establishing a bridge between the institution and society through the media. This will only beachieved through well-defined strategies of approach and care in communicational processes that must occureven before the actual installation of the crisis, identify in gandreducing vulnerabilities through frequent meetings between crisis cabinet components. The refore, it is imperative an institution which values its imagean dreputation must, everyday, seekways to strength em these intangible as set sbyempowering its Professionals and eliminatin gorreducing the risks of a crisis, learning fromother institutionsm is takes through case studies orevenwith their ownmistakesso crisis moments do notreach the institution again. Given this, the área of communication is und oubtedlyone of the most important areas in crisis management, having the capacity to solve oreven aggravate a crisis.
\end{abstract}

Keywords: crisis management. press office. communication. public communication. 


\section{INTRODUÇÃO}

Há um enfrentamento diário do profissional que assume a assessoria de comunicação de uma instituição pública qualquer a problemas operacionais que se referem ao negócio da organização. Acusações verdadeiras e falsas envolvendo o serviço prestado pelas instituições, a imagem institucional, a credibilidade e a marca são uma realidade, mas tão real quanto a ameaça dessas acusações é a ausência da cultura prevencionista por parte dos gestores e a ausência de treinamentos sobretudo na área de gestão de crises através da comunicação, não sendo a comunicação social nesses órgãos uma prioridade. Ainda existe o pensamento de evitar debater o gerenciamento preventivo de uma crise por achar ser um desprendimento de tempo desnecessário e não prioritário, podendo ser realizado quando a crise houver sido instalada e que preparar-se para uma potencial crise seria assumir que a gestão comete falhas (ALVES, 2007, p.89-90).

Assim, com o surgimento da crise, a instituição deposita sobre o assessor de comunicação responsabilidades que fogem de suas atribuições, como por exemplo, o gerenciamento da crise, limitando-se o entendimento da crise tão somente como uma repercussão midiática de um fato que poderá ser tratado através da boa comunicação de um assessor, esquecendo-se as possíveis repercussões legais, financeiras, operacionais e sociais existentes. Esse tipo de abordagem acaba por não gerar resultados efetivos para a organização podendo estender o tempo de existência da crise ou, por vezes, até agravá-la pela inexistência de uma base de gestão de crise forte.

Este trabalho tem como objetivo demonstrar o papel do assessor de comunicação no gerenciamento de crise frente a informações negativas referentes à instituição a que pertence, trazendo definições do que é a crise e a ameaça que ela representa para uma instituição. $O$ trabalho traz ainda sugestões quanto à composição de um gabinete institucional para 0 gerenciamento de crises e uma visão preventiva pautada no estudo de caso a 
fim de que se evite o surgimento de crises ou que seu potencial de causar danos seja, se não anulado, reduzido através dessa visão de preparação para enfrentamento de adversidades.

\section{OBJETIVOS}

- Identificar a ameaça representada por uma crise a uma instituição.

- Definir estratégias de comunicação institucional frente a adversidade.

- Identificar o papel do Assessor de Comunicação no Gerenciamento de Crise em uma instituição.

\section{MÉTODO}

Trata-se de uma revisão bibliográfica narrativa, ou seja, uma pesquisa baseada na análise da literatura já publicada em forma de livros, revistas, publicações avulsas, imprensa escrita eletronicamente, disponibilizada na Internet.

A abordagem foi qualitativa, segundo Goldenberg, (1997, p.34) que afirma que "a pesquisa qualitativa não se preocupa com representatividade numérica, mas, sim, com o aprofundamento da compreensão de um grupo social, de uma organização, etc.".

Os procedimentos seguiram a definição de Minayo (2001, p.14), para pesquisa bibliográfica: "os exemplos mais característicos desse tipo de pesquisa são sobre investigações sobre ideologias ou aquelas que se propõem à análise das diversas posições acerca de um problema. "

A pergunta norteadora utilizada para direcionar o estudo em questão foi: Como comunicar uma informação negativa relativa a uma instituição pública enquanto assessor de comunicação no gerenciamento da crise? 
A partir do conteúdo encontrado no material pesquisado, foram construídos os capítulos da pesquisa em questão.

\section{REFERENCIAL TEÓRICO}

Há diversas definições para a palavra "crise", mas, com o foco na crise que tem a capacidade de atingir uma instituição pública ou privada pode-se citar a seguinte definição: "Crise é um evento que traz ou tem o potencial de trazer à instituição uma futura ruptura na sua lucratividade, seu crescimento e, possivelmente, sua existência" (LERBINGER apud OLIVEIRA, 2007, p.165).

Entendendo-se a crise então como esse evento que representa uma ameaça real para a instituição é necessário identificar suas particularidades e classificar conforme suas características. Pensando nisso Oliveira, (2007, p.165) buscou classificar as crises assumindo que possam ser crises do mundo físico, classificando-as então como naturais ou tecnológicas; crises de clima humano, classificando-as como de confronto, de malevolência e de distorção de valores administrativos; e crises de falha administrativa, classificando-as como de decepção e de má administração.

As crises do mundo físico naturais tratam-se dos fenômenos da natureza onde não há culpa humana e são aceitas como fatalidades, dando-se como exemplo os furacões, as tempestades e os terremotos (OLIVEIRA, 2007, p.165).

As crises do mundo físico tecnológico são atribuídas ao homem e resultam da manipulação dos recursos presentes no ambiente criando riscos que não existiam, tais como, a criação de usinas nucleares ou o implante de silicone, onde a responsabilidade das ocorrências recai sobre as empresas (OLIVEIRA, 2007, p.166).

As crises de clima humano de confronto são as que envolvem a ação de grupos organizados como o movimento dos sem terra, movimento dos sem teto, organizações não governamentais, na busca de defenderem seus 
interesses, pressionando as instituições, no caso deste trabalho admita a instituição pública, a fim de que ajam de acordo com seus objetivos (OLIVEIRA, 2007, p.166).

As crises de clima humano de malevolência acontecem quando grupos ou indivíduos agem de forma ilícita intencionalmente a fim de causar danos à imagem de uma instituição, seja por boatos ou mesmo por terrorismo (OLIVEIRA, 2007, p.167).

Crises de clima humano de distorção de valores administrativos são geradas a partir do emprego de recursos em benefício de um grupo causando insatisfação em outro grupo. Dá-se como exemplo a crise gerada através da concessão de aumento a funcionários públicos da educação sem que sejam contemplados os funcionários da saúde ou segurança (OLIVEIRA, 2007, p.167).

Crises de falha administrativa de decepção se dão quando o serviço ou produto anunciados por uma instituição não correspondem com a realidade deixando um público desconfortável quanto à veracidade do anúncio daquele produto ou serviço. É o que ocorre quando se anuncia a execução de uma obra de saneamento que acaba não atendendo às necessidades de um público ou que finda por inacabada (OLIVEIRA, 2007, p.167).

As crises de falha administrativa de má administração caracterizam-se pelos atos ilegais ou imorais que são executados pelos responsáveis pela administração da instituição. São exemplos os casos de desvio de verba pública (OLIVEIRA, 2007, p.168).

\subsection{A Crise Na Instituição}

A crise é um evento que normalmente surpreende os membros de uma organização produzindo riscos e inclusive ameaçando a sobrevivência da instituição. Devido à sua possibilidade de causar danos, exige-se uma resposta rápida, porém organizada. Apesar de ser observada como um acontecimento 
repentino, na verdade a crise é um processo progressivo de degeneração cuja prevenção, através de observação vigilante e estudos de casos, tem sido a melhor forma de lidar com a possibilidade de surgimento dessa adversidade (SHINYASHIKI, 2007, p.152).

As crises institucionais, diferente do que se pode aduzir, vão muito além de incêndios, explosões, desabamentos, desastres naturais, danos ambientais e vazamento de materiais perigosos. Elas podem ser geradas em pequenos problemas internos que são conhecidos por gestores e funcionários e que, ao invés de se ter uma resolução, acabam sendo tolerados e permanecem por um longo período de tempo na instituição até que sejam insuportáveis, de difícil resolução e provoquem uma grande crise (ALVES, 2007, p.97).

No mesmo sentido, Forni (2007, p.200) afirma que esses pequenos problemas internos podem ter início em diversos setores de uma instituição, como na realização de transações ilícitas conduzidas pelo setor financeiro; na área operacional, seja pela má prestação de serviço à sociedade ou mesmo pela utilização indevida dos recursos materiais e humanos do órgão; na gestão do órgão onde se negligencia leis e áreas da instituição que julga não prioritárias ou mesmo na segurança, sejam elas de informações ou de suas instalações.

Não se admite nos dias de hoje escândalos de corrupção, improbidade administrativas e favorecimentos indevidos que envolvam instituições públicas, mas é uma realidade o surgimento de crises por esses motivos. As instituições públicas devem atuar conforme o que dispõe as leis de administração pública a fim de oferecerem serviços de qualidade da melhor forma possível. Em um momento em que o país é bastante observado pela imprensa, pela indústria das ações judiciais e por um poder judiciário atuando como nunca "quem sai da linha, em geral, é levado a uma grande exposição negativa e permanece por um bom tempo sob os holofotes da opinião pública" (ALVES, 2007, p.93).

Para que uma instituição não enfrente problemas dessa ordem, é necessário que se tenha uma preparação evitando-se dias maus. Nos Estados 
Unidos da América a abordagem a uma crise começa antes mesmo de sua instalação, inicia-sepelos chamados estudos de casos. Lá se tem como objeto de estudo os acontecimentos nas empresas e a partir daí se preparam para que não aconteça o mesmo com a sua instituição, fazendo com que os erros identificados não se repitam, antecipando-se assim a uma possível crise. Esse tipo de abordagem mostra o quanto é importante o aspecto preventivo para um bom gerenciamento. A prevenção a uma crise passou então a ser um grande negócio onde já se divide o estudo para áreas específicas: educação, segurança, saúde e áreas diversas (FORNI, 2007, p.200).

A realidade no Brasil é bem diferente do que já se tem no exterior. Não há uma visão preventiva para abordar uma crise. O que se observa são instituições fazendo declarações precipitadas ou intempestivas, buscando-se fuga do que se pergunta, ou até procurando esconder fatos ao invés de trazer esclarecimentos. Esse tipo de erro resulta em uma percepção do problema pelo público alvo com pouca transparência, e a mídia, por sua vez, aproveita o momento oportuno para dar notoriedade à comunicação confusa, sendo este fato extremamente negativo para a instituição (FORNI, 2007, p.201).

Alves (2007, p.98) afirma, em concordância com Forni, que "alguns órgãos governamentais no Brasil simplesmente não se comunicam ou se comunicam muito tarde quando o assunto é delicado. A opinião pública fica à mercê de fontes leigas". São esses fatos que dão ainda mais ênfase ao fato de que "as organizações brasileiras não estão preparadas para enfrentar crises, principalmente quando a situação se torna grave, independente da atividade". (FORNI, 2007, p.199).

As instituições que abriram os olhos para preparar seus profissionais para situações de crise acabaram por limitar-se ao relacionamento com a imprensa, não lembrando de outros públicos, como o interno, por exemplo, e nem tampouco focaram em medidas que pudessem evitar a aparição da crise 0 que evitaria desgastes com a imprensa e danos à imagem da corporação e outros danos possíveis (FORNI, 2007, p.199). 


\subsubsection{O CUIDADO COM OS BENS INTANGÍVEIS}

Para Alves (2007, p.96), a crise atinge aspectos tangíveis da instituição, como o patrimônio material e financeiro, e intangíveis, como a marca, a reputação e a imagem e podem estar relacionadas tanto com problemas operacionais como com desvios de conduta administrativa e problemas sociais como discriminações e assédios ocorridos na instituição. O setor de comunicação ou relações públicas de uma instituição lida diretamente com os bens intangíveis do órgão.

Lopes (2005, p.74) afirma em seu trabalho que a reputação e a boa imagem são importantes para uma instituição e para que possa obtê-las é preciso um trabalho de longo prazo, fundamentado na construção e na manutenção de bons relacionamentos com seus diversos públicos. Elas então assumem papel indispensável para que uma instituição sobreviva.

Essa capacidade de sobreviver pode ser constatada através da afirmação de Melo (2007, p.127) onde diz que um acidente pode ser mais bem aceito se a organização gozar de uma boa credibilidade sustentada em sua reputação sólida. Por outro lado, um pequeno incidente pode gerar grande problema público se a instituição tem sua imagem ou reputação questionáveis. A fim de que se entenda o prejuízo de macular a imagem e reputação institucional pode-se citar problemas vividos ainda hoje por empresas que tiveram suas imagens maculadas e que há anos buscam resgatar sua credibilidade, como é o caso da Nike que tem sua imagem manchada pela possibilidade de ter explorado o trabalho infantil, ou podemos citar a Merck por ter demorado a tirar do mercado um medicamento que sabidamente causava problemas à saúde (BUENO, 2005, p.17).

Imagem e reputação, já apresentadas como bens intangíveis, são diferentes em seus significados e no que representam para a instituição. A identidade é mais do que a identificação visual de uma empresa, compreende o que a empresa é, o que faz, o que diz e como diz e faz. É importante entender 
que a comunicação com o público interno e externo também é componente da identidade de uma instituição. A identidade corporativa emana da instituição para o seu cliente, a sociedade. É como a empresa constrói sua essência a fim de que possa ser percebida. Já a imagem e a reputação estão ligadas a como a sociedade percebe a instituição. A imagem pode ser diferente dependendo do público. A imagem pretendida diz respeito a como a instituição se vê e quer ser vista, já a imagem real é como o seu cliente a vê e a autoimagem descreve como a instituição é vista pelo seu público interno. Semelhante à imagem a reputação surge da percepção do cliente, a sociedade, no entanto a reputação é uma imagem construída ao longo do tempo, algo ligado à vivência e experiências de relação com a instituição ao longo de anos. Torna-se então mais fácil modificar a imagem de uma instituição do que a sua reputação. Neste contexto, o setor de comunicação se insere a fim de aproximar a identidade corporativa da imagem pretendida, gerando uma imagem real e uma autoimagem mais próxima do que ambiciona a instituição e resultando numa reputação positiva para o órgão (BUENO, 2005, p.17-18).

Fica assim caracterizada a importância da comunicação institucional que ganha espaço como bem intangível com a característica de poder agir positivamente nos relacionamentos. Na gestão de crises ela possibilita a construção, manutenção e preservação da identidade e reputação de uma organização ou instituição, à medida que cuida da imagem a ser formada pelo público, em todo e qualquer ponto de contato com a organização ou instituição (RODRIGUES, 2017, p.262).

\subsection{A Composição e Ação Efetiva do Gabinete de Crise}

Toda instituição pública está sujeita a, em algum momento, deparar-se com a situação de crise e deve estar pronta para geri-la. Gerir uma crise, no entanto, é muito mais que estar à frente do órgão no período adverso esperando o resultado final do evento danoso. A gestão de crises pode ser 
definida como um conjunto de ações realizadas por gestores com o objetivo de evitar, prevenir e solucionar as situações de degeneração enfrentadas pelas instituições e que as permitam voltar para as suas situações normais de funcionamento (SHINYASHIKI, 2007, p.155).

"Às vezes, o mal gerenciamento de uma crise pode causar mais danos para uma empresa do que a própria crise", afirma Smith (2005, p.4 apud ALVES, 2007, p.90) em sua obra Crisis Leadership. A maneira com que se conduz a informação numa crise pode revelar inúmeros outros aspectos negativos de uma ação ou serviço prestado agravando-a e expondo ainda mais a instituição. A ação ou serviço causador da crise pode acabar tendo, através do mal gerenciamento, um valor de menor relevância diante do prejuízo gerado por uma declaração infeliz.

Arribas (2016, p.180) afirma que uma ameaça a uma organização requer uma avaliação das demandas, bem como quais recursos estão disponíveis para lidar com ela. Esse procedimento não é realizado através de uma pessoa isoladamente, mas, por meio de um grupo de pessoas que conhecem a instituição e que podem intervir efetivamente para a anulação da ameaça. A essa equipe dá-se o nome de gabinete de crise ou comitê de crise.

$\mathrm{Na}$ composição dessa equipe estão integrantes de áreas estratégicas da instituição. Recomenda-se que todos os integrantes se reúnam periodicamente a fim de planejarem ações preventivas que visem reduzir a possibilidade de ocorrência de uma crise. Se já instalada, que se reúnam a fim de agir rapidamente para superar a situação adversa, estando disponíveis 24horas por dia caso seja necessário para acordarem tomadas de decisão (ABRAPP, 2015, p.14-15).

A composição do gabinete de crise é sugerida pela ABRAPP (2015, p.14) que apresenta alguns setores estratégicos da organização e uma função muito importante nessa composição. Deve-se definir então o Porta-voz e um substituto, podendo assumir essa função o representante legal da instituição ou o responsável pelo setor de relações públicas, se assim for definido pelo 
gerente da crise. A assessoria de imprensa, bem como a assessoria jurídica, o responsável pela segurança das informações e diretores e gestores completam o pessoal envolvido na gestão da crise.

O gerente da crise deve ser alguém com autonomia para tomar decisões. Segundo Alves (2007, p.93) ele deve "trabalhar para que a instituição enfrente a mínima exposição negativa, com classe e sem sequelas". Com ele completa-se o gabinete de crise. Sua função é estar à frente do grupo e de todo o processo de gestão de crise.

Esse processo de gestão de crises pode ser dividido em cinco fases distintas. Segundo Shinyashiki (2007, p.155) essas fases podem se dividir em: detecção de sinais; prevenção; contenção (limitação dos danos); recuperação e aprendizagem que serão abordados sucintamente na sequência.

$\mathrm{Na}$ fase de detecção de sinais compreende-se a vigilância na observação de possíveis falhas ou eventos que potencializam o surgimento de uma crise. Essa observação dá a possibilidade de evitar a crise ou ao menos responder de forma rápida.

$\mathrm{Na}$ fase de prevenção, está a preparação da instituição para evitar a crise. Essa prevenção pode ser firmada através de estudos de casos que permitam minimizar o aparecimento dos sinais da crise já estabelecendo uma possível conduta a ser adotada caso se instale. Quanto a essa fase, Forni (2007, p.210) afirma que "a gestão de risco é a antecipação do que pode acontecer, pensando tudo o que pode dar errado", e ainda que "uma instituição que não deseja se vê em meio a uma crise deve ter um sistema preventivo de crise, monitorando os pontos vulneráveis, com um plano de contingência para as situações de risco", ou seja, gestão de risco é prevenir. Na mesma linha de raciocínio, Arribas (2016, p.180-181) explana que em uma estrutura de planejamento em gestão de crises é muito importante a criação de uma lista de possíveis variáveis que podem influenciar na tomada de decisão quanto à melhor resposta da organização para determinada situação. 
Percebe-se facilmente a preocupação de alguns autores em enfatizar, dentro do processo de gestão de crise, a importância da prevenção. Essa é uma tendência atual nesse processo que facilita as ações em todas as demais fases da abordagem à crise. Quando a instituição deseja evitar que a crise seja gerada internamente deve observar suas áreas vulneráveis. Com essa premissa pode-se identificar nas áreas da instituição que atividades poderiam de alguma maneira gerarem processos indesejáveis, não éticos ou ilegais. Outra forma de prevenção é a descentralização de poderes de áreas importantes e mais sensíveis da instituição com a aprovação de processos em duplo sim, onde se faz necessária a aprovação de mais de um indivíduo para que se formalize uma ação. Finalmente deve-se aplicar sanções exemplares para os atos errados possíveis geradores de crises (SROUR, 2013 apud ARRIBAS, 2016, p.181).

Dando-se seguimento, tem-se a fase de contenção. Nela a instituição deve colocar em prática tudo o que foi preparado na fase de prevenção a fim de que haja a limitação dos danos; Segue-se então a fase de recuperação, onde a empresa reconstrói o que foi destruído, sendo bens tangíveis ou intangíveis, e sana os problemas setoriais, buscando a normalidade.

Por fim, a fase de aprendizagem, onde a crise enfrentada serve como caso a ser estudado para que se evite crises da mesma natureza e que se estabeleçam procedimentos para o melhor enfrentamento de uma crise futura (SHINYASHIKI, 2007, p.155).

Entendidas as fases do gerenciamento de crise, o desafio é iniciar a abordagem à crise propriamente dita. Para Arribas, (2016, p.180) a abordagem a uma ameaça pode ocorrer de formas diferentes. Fatores internos e externos podem influenciar a forma com que se lidará com o problema. Apesar das maneiras diferentes de se abordar uma crise, uma premissa é certa em todas as situações: a preocupação inicial com o surgimento da crise para um bom gerenciamento é entender o que está acontecendo de forma segura para enfrentar o problema com propriedade (ABRAPP, 2015, p.14). 
Shinyashiki (2007, p.155-156) agrupa ainda algumas observações importantes na gestão de crises, as quais separa em 10 categorias, conforme segue:

a. Prevenção de crises: é importante planejar e formalizar ações de prevenção para evitar a crise ou minimizar os danos oriundos dela;

b. Planejamento e procedimentos de contingências: Planejar-se para agir em diversos cenários possíveis para manter a instituição viva;

c. Atenção direcionada aos stakeholders: as pessoas não devem ser ignoradas, sejam clientes, funcionários ou investidores, a atenção deve ser direcionada a todos;

d. Comprometimento da direção: a resolução de uma crise depende do envolvimento direto da direção da instituição e da prioridade dada à crise;

e. Comunicação: deve-se ter uma equipe especifica para agir em questões que envolvam a reputação da instituição, garantindo informações confiáveis a todos os públicos;

f. Estímulos da liderança: no gerenciamento de uma crise, o líder é um apoio emocional, provedor de confiança e direcionador da instituição;

g. Manutenção dos valores organizacionais: a instituição em crise não deve se desviar dos valores que a orientam. Honestidade, transparência e respeito fortalecem o gerenciamento efetivo de uma crise;

h. Criatividade: ideias novas para identificação da causa do problema e de alternativas viáveis e efetivas para sua superação devem ser incentivadas;

i. Rapidez nas ações: uma ação organizada e rápida na primeira hora após o surgimento da crise pode determinar a eficácia do seu gerenciamento;

j. Cuidados pós-crise: cuidar das consequências da crise é tão importante quanto aprender com a crise e evitar que se repita. 
Uma dessas observações realizadas por Shinyashiki merece atenção neste trabalho: a comunicação. Dentro do gabinete de crise pode-se destacar o profissional de comunicação que assume a grande responsabilidade de comunicar-se com os públicos interessados pelo pronunciamento da instituição, conforme orientação do gerente de crise, e deverá fazê-lo de forma responsável e que esclareça o que realmente a instituição deseja comunicar a fim de que evite danos ou minimize os resultados negativos em uma crise (FORNI, 2007, p.200).

É um erro, porém, é a realidade em algumas instituições públicas, acreditar que o gerenciamento de uma crise pode ser realizado exclusivamente com o setor de comunicação por haver profissionais bons, e não envolver no gerenciamento setores importantes da instituição, inclusive o setor gerador da crise, para resolução de problemas. Ações resolutivas são de responsabilidade da instituição a partir de decisões do gabinete de crises que fará a sua parte que somada à atividade do setor de comunicação ensejará no atendimento efetivo para direcionamento de uma crise. Neste sentido, Forni se pronuncia em entrevista à revista Organicom sobre a Comunicação em tempos de crise:

\begin{abstract}
Você pode ter excelentes profissionais de comunicação, estratégia perfeita para neutralizar notícias negativas e até um bom relacionamento com a mídia. Mas se os fatos geradores da crise não forem conduzidos com eficiência, transparência e profissionalismo, esse trabalho na comunicação não adianta. A empresa tem que fazer a sua parte da melhor maneira possível, administrar todos os passivos gerados por uma crise e, então, a comunicação entra fazendo a sua parte. Por vezes, existe confusão entre gerenciar a comunicação na crise e administrar a crise propriamente dita. 0 executivo não pode esperar que a comunicação sozinha resolva a crise da empresa (FORNI, 2007, p.200).
\end{abstract}

\title{
4.2.1 O PAPEL DO ASSESSOR DE COMUNICAÇÃO
}

Alves (2007, p.93) afirma que "é nos momentos das crises que as empresas se dão conta de suas fragilidades e que a maior das batalhas se dá na área da comunicação". Essa afirmação se aplica também quando falamos 
das crises ocorridas em instituições públicas, pois, nelas se espera que a ação do setor de relações públicas ou comunicação seja efetivamente capaz de resolver por si só a situação adversa.

O setor de relações públicas age, na verdade, no entendimento de Arribas (2016, p.178),como uma "ferramenta de direcionamento que estabelece e mantém relações mutuamente benéficas entre a organização e o público, dependendo dessa relação o seu êxito ou o seu fracasso". A sua função é cumprida ao longo de toda a vida da instituição, fortalecendo a relação da instituição e a sociedade, e não somente no momento da crise, porém, é na crise quese percebe o valor do trabalho realizado através da imagem, reputação e credibilidade solidificada da instituição que permite que a crise seja enfrentada com maior facilidade. O setor, "visa formar a imagem da instituição a ser percebida por públicos diversos, o conceito baseado em ações e informações, opinião pública e atitude através da comunicação motivadora do público em benefício da instituição" (LOPES, 2005, p.79).

Quando se vivencia uma crise numa instituição pública percebe-se o surgimento de conflitos, sejam eles vindos da relação do órgão com os meios de comunicação, com o público interno ou com a sua cliente, a sociedade. Arribas (2016, p.180) diz que a influência das relações públicas no decorrer de um conflito pode implicarnaredução de conflitos, o que normalmente acontece na gestão de crisesatravés da atuação do assessor de comunicação ou assessor de imprensa da instituição.

Neste cenário todos os atores do gabinete de crise devem ter uma atribuição específica que, somadas, colaborem para o fim da crise. Ao assessor de comunicação, segundo a Federação Nacional dos Jornalistas (2007, p.7), "compete facilitar a relação entre a instituição e os formadores de opinião". Espera-se ainda que o assessor de comunicação tenha a capacidade para efetuar planos estratégicos, tanto na fase de prevenção a uma crise, traçando possíveis formas de ação, quanto durante a crise, adaptando-se às 
particularidades de cada crise;e gerir a reputação da instituição a qual pertence (OLIVEIRA, 2010, p.28).

Durante uma crise o assessor de comunicação deve buscar sempre antecipar-se à imprensa quanto às necessidades de informação, pois os meios de comunicação são o veículo através do qual a maior parte da sociedade estará sendo esclarecida dos fatos. Antecipar-se a essas necessidades compreende descobrir, com o auxílio dos demais componentes do gabinete de crise, o que ocorreu, fazendo um levantamento completo da situação, com dados verdadeiros e atualizados e preparar um texto ou discurso descrevendo o fato gerador da crise informando as providências que estão sendo tomadas pela instituição, de forma clara. Esse processo de construção da informação deverá ser realizado a todo instante com acréscimo de novas informações.(FEDERAÇÃO NACIONAL DOS JORNALISTAS, 2007, p.15).

Há uma necessidade de que essas informações sejam organizadas de forma a não deixar lacunas e com brevidade para que se evitem danos à instituição e ao Estado. Quanto maior o tempo em responder aos questionamentos dos públicos, principalmente das vítimas, parcela da sociedade diretamente prejudicada com a crise; da imprensa, que tem a necessidade de informação e é uma grande formadora da opinião pública; do Governo, que tem o poder de aplicar sanções e no caso das instituições públicas é responsável pelas consequências da crise; do público interno, que é um dos principais alicerces da instituição, maior será o potencial da crise de tomar proporções que fujam ao controle da instituição públicaque está no processo de gerenciamento da crise (OLIVEIRA, 2007, p.164).

$O$ assessor de comunicação deve ser a fonte de toda a informação que chega ao gerente da crise de maneira a evitar informações incoerentes e inverídicas. Ele garante que a informação está organizada, tratada e coerente, pronta para ser utilizada em pronunciamentos da instituição no processo comunicacional da instituição com seus públicos. Tavares et al $(2015$, p.7) afirmam que "na prática, o profissional que trabalha na assessoria atua como 
Revista Científica do Corpo de Bombeiros Militar de Pernambuco

Artigo Publicado no Vol.05 N.13 - Edição Jul a Dez 2019 - ISSN 2359-4829

Versão on-line disponível em: http://www.revistaflammae.com

facilitador deste processo, no qual seu papel fundamental é colaborar: fornecendo as informações necessárias, das mais básicas às mais elaboradas".

Todo o trabalho do assessor de comunicação se reflete através dos resultados que são obtidos por meio da condução da informaçãoneste processo de interação comunicacional onde a instituição se comunica com a sociedade em relação respeitosa, responsável e comprometida, esclarecendo os fatos e ações desenvolvidas para anulação ou redução dos danos oriundos da crise (CARNIELLI, 2017, p. 67).

\subsubsection{A NECESSIDADE DE AÇÃO INTEGRADA}

Por certo, há uma cobrança sobre o setor de comunicação de instituições públicas onde se espera os resultados positivos de atribuições que não são competências do setor, mas que acabam sendo atribuídas por simples tradicionalismo e falta de conhecimento de gestão de crise por parte da instituição. A cobrança vem ainda acompanhada da falta de apoio, caracterizada muitas vezes pela omissão de sugestões ocasionada pelo receio de haver envolvimento em ação que possa prejudicar a instituição, embora se busque o seu fortalecimento. Para Rodrigues (2017, p.263) a alta administração de uma instituição pública deve dar pleno apoio para que se estabeleça uma comunicação transversal que atinja todos os segmentos institucionais com o mínimo de ruído possível.

Esse tipo de situação demonstra a fragilidade de uma instituição frente a uma crise.A cultura de trabalho integrado prevê inclusive que haja planejamento preventivo com atribuições preestabelecidas para 0 enfrentamento da adversidade a fim de que se preserve a instituição. "Quando existe um planejamento antecipado de prevenção e gerenciamento de crises, a cultura da integração é fortalecida. Somam-se esforços para preservar e proteger a reputação da empresa" (OLIVEIRA, M.F., 2007, p.165). 
Diante de uma crise, tem maior possibilidade de superar o problema a instituição que consegue agir de forma integrada. $O$ trabalho em equipe permite discutir uma possível adversidade de forma a identificar vulnerabilidades e tratar de resoluções para evitá-las, atribuindo à equipe boa capacidade de contornar problemas. O resultado desse trabalho é uma instituição com imagem e reputação sólidas que tem credibilidade diante dos seus diversos públicos. Melo (2007, p.128) afirma que "a postura do público é influenciada pela capacidade de controle da situação ou de sua aparência" e ainda acrescenta que o público expressa uma reação negativa quando estão diante de situações que the parecem ser injustas e poderiam ser perfeitamente evitadas.

\subsection{A Comunicação no Gerenciamento de Crises}

A crise é um momento que exige da instituição pública uma boa comunicação em respeito ao princípio da publicidade e à sociedade. Essa comunicação tem como característica ser constante, compreensível e verdadeira, demonstrando efetivamente o cuidado do Estado para com o cidadão. Matos (1999, p.2-3 apud RODRIGUES, 2017, p.262) afirma que "a comunicação pública envolve o cidadão de maneira mais diversa, participativa, estabelecendo um fluxo de relações comunicativas entre o Estado e a sociedade".Carnielli (2017, p.67) ainda acrescenta que a comunicação pública "traduz a democracia no sentido de que operacionaliza critérios democráticos fundantes como acessibilidade e discutibilidade, a partir dos quais são processadas as exigências de legitimidade do exercício do poder".

Esse cuidado do Estado para com a sociedade além de ser real precisa ser percebido por ela. A partir dessa premissa tem-se como objetivo da comunicação pública uma defesa argumentativa, fundamentada, de um valor através de narrativas que possam confirmar a validade do valor e da instituição 
Revista Científica do Corpo de Bombeiros Militar de Pernambuco

Artigo Publicado no Vol.05 N.13 - Edição Jul a Dez 2019 - ISSN 2359-4829

Versão on-line disponível em: http://www.revistaflammae.com

que o representa, fazendo da comunicação um elo entre o Estado e seus públicos numa relação cada vez mais próxima (CARNIELLI, 2017, p.68).

Manter o relacionamento de proximidade com os públicos de interesse das organizações tem sido um grande desafio atualmente enfrentado pelas assessorias de comunicação das instituições públicas. Esse relacionamento não se trata tão somente de produzir conhecimento para que as instituições consigam tratar de problemas internos ou externos, mas um relacionamento capaz de cativar o público a ponto que saberem das possibilidades e limitações da instituição, principalmente diante de uma possível crise (HENRIQUES, 2017, p.34).

Para isso as assessorias de comunicação das instituições públicas têm como funções criar um plano de comunicação como importante instrumento no relacionamento com a imprensa, onde trabalho continuado de assessoria de comunicação permitirá à instituição criar um vínculo de confiança com os veículos de comunicação e sedimentar sua imagem positiva na sociedade, e com os púbicos internos e externos da instituição; esclarecer para a sociedade o papel da instituição; demonstrar comprometimento da instituição com os seus públicos apresentando seus valores e estabelecer uma relação de confiança com os veículos de comunicação (FEDERAÇÃO NACIONAL DOS JORNALISTAS, 2007, p.6-7).

Preparar-se para uma possível crise também é necessário para a assessoria de comunicação, sendo a criação desse vínculo de confiança, parte dessa preparação, bem como o planejamento estratégico. A prevenção deve permear todas as áreas em que a comunicação está envolvida a fim de se evitar a crise. "Na política de prevenção de crises, o mundo virtual também deve ser contemplado" afirma Forni (2007, p.209). Se não houver uma boa estrutura de tecnologia de informação capaz de identificar invasões, neutralizar ataques de hackers, denunciar ataques virtuais e até mesmo retirar do ar para manutenção o portal, blog, ou rede social, deve-se avaliar se realmente é 
necessário ser mantido esse canal de comunicação com o público alvo a fim de que não haja problemas geradores de crises.

Segundo Bueno (2005, p.13), no Brasil, a comunicação institucional ainda está muito focada no operacional, onde o tático está acima do estratégico, a resposta a uma crise acima de sua prevenção, embora os discursos dos representantes das instituições aparentem exatamente 0 contrário. Bueno (2005, p.14) afirma ainda que a pesquisa de comunicação, ferramenta necessária para se conhecer a efetividade da comunicação institucional, não faz parte do dia a dia das organizações de maneira geral, sendo tratada como despesa e não como investimento, não compondo efetivamente o planejamento das instituições e apenas este fato é suficiente para desmistificar o caráter estratégico com que se tipifica a comunicação das instituições brasileiras.

Acredita-se que preparar-se para uma crise é oferecer um treinamento do que fazer durante a crise. Investir na prevenção da crise é uma ação bastante significativa para o bom gerenciamento dela, sobretudo na área de relações públicas ou comunicação da instituição. Vale ressaltar que o setor de comunicação não gerencia a crise, essa tarefa é desempenhada por um gerente específico em um gabinete de crises, no entanto, comunicação é um dos pilares mais importantes para se gerenciar uma crise (FORNI, 2007, p.199).

É importante deixar claro que desenvolver um manual para crise e ter um curso de media training, apesar de serem ações necessárias, não são suficientes para que se tenha executado o planejamento preventivo de uma crise. Deve-se entender a administração de uma crise como algo sistêmico. Essas ações fazem parte de um sistema de medidas essenciais para se agir preventivamente a uma crise juntamente a outras que podem também ser operacionais além de preventivas, como: resposta a situações de emergência, a comunicação durante a crise, a comunicação de riscos, o gerenciamento da crise, o plano de crise, o manual de comunicação de crise e o estudo de 
Revista Científica do Corpo de Bombeiros Militar de Pernambuco

Artigo Publicado no Vol.05 N.13 - Edição Jul a Dez 2019 - ISSN 2359-4829

Versão on-line disponível em: http://www.revistaflammae.com

vulnerabilidades. Sobre isso, Alves (2007, p.95) afirma ainda que "a análise de riscos operacionais com o estudo das vulnerabilidades à crise pode abranger quase $100 \%$ das possibilidades de antecipação à crise".

Superada ou instalada a crise, para Alves (2007, p.98) "o desafio é comunicar sem causar pânico, revolta ou indignação".É o momento de colocar em prática tudo o que foi planejado para o enfrentamento da crise, de buscar informações e comunicar-se com os públicos interessados, podendo, para isso, fazer uso dos meios de comunicação, aproveitando a boa relação fortalecida com a imprensa ao longo do período anterior à crise. Sobre essa comunicação, Batista (2007, p.103) afirma da seguinte maneira:

\begin{abstract}
A comunicação de riscos, um campo de estudos que teve como força inicial o interesse em transmitir informação técnica de peritos para 0 público leigo, focando principalmente o papel da mídia nessa transmissão de conhecimento, pode ser tratada como uma das formas de relacionamento com os públicos de interesse das empresas; assim, visa tanto informar sobre algum tipo de problema que possa ser causado pela instalação, produção e outros aspectos dessas empresas, como fornecer ferramentas para que o público possa lidar com os fatores que desencadearam a necessidade da comunicação.
\end{abstract}

\title{
4.3.1 PRECEITOS BÁSICOS NO GERENCIAMENTO DE CRISE
}

Diante de uma infinidade de possibilidades de desdobramento de uma crise, a definição de princípiospara que se possa geri-la pode ser um uma ferramenta muito importante para que a instituição pública seja considerada resiliente. A esses princípios, Forni (2007, p.210) chamou de preceitos básicos, afirmações irrefutáveis do que se possa fazer ou se deva evitar numa crise.

Forni (2007, p.210) afirma que "Se não quer que publique, não faça": Essa afirmação traz consigo uma reflexão: se o que está sendo executado é moral, ético e legal, não teria problema algum de ser publicado, mas, se a publicação poderia trazer juízo de valor negativo sobre a ação, essa ação deve ser repensada e corrigida. Não se admite mais os "jeitinhos" da administração para que um trabalho seja executado ou facilitado. $\mathrm{O}$ autor afirma ainda que a 
maioria das crises é decorrente de erros de gestão, ratificando a importância de uma boa gestão.

Para Melo (2007, p.128), conhecer a necessidade da mídia é também um princípio a ser observado. Esse conhecimento é alcançado através de outro princípio afirmado por Forni, (2007, p.210) onde escreve que deve ser dada atenção para que se possa"manter uma relação cordial com a imprensa e não a procurar só na hora da crise". O trabalho contínuo do setor de relações públicas ou de comunicação de uma instituição deve ser de aproximação e fortalecimento da relação da instituição com os profissionais da imprensa a fim de que se obtenha credibilidade e confiança quanto às informações que serão prestadas e suas corretas publicações (FORNI, 2007, p.210).

Outra afirmação de Forni (2007, p.210) é feita no sentido de "não economizar tempo e informação para explicar uma pauta negativa, por pior que seja". A informação precisa ser transmitidaindependente de sua valoração negativa a fim de esclarecer o fato. Fugir da crise ou de seu esclarecimento gera desconfiança e descrédito da instituição e ainda agrava as consequências de uma crise, sendo uma omissão danosa para a instituição pública.

Para tanto, a comunicação deve ser estabelecidaatendendo ao preceito de que se deve"Falar a verdade acima de tudo, não tentando esconder nada, $o$ que gera algo importantíssimo na crise: credibilidade", conforme expõe Forni(2007, p.210). Melo (2007, p.128) concorda ainda com esse princípio fazendo a observação de que a comunicação deve ser honesta, aberta e franca.

A instituição pública tem a missão de ser a primeira a buscar informações sobre o evento causador de uma crise e realizar seus pronunciamentos sobre os fatos. Essa ação atende ao preceito trazido também por Forni (2007, p.210): "Antecipar-se, ser proativo e não reativo". Esse preceito é muito próximo a outro proposto pelo autor onde expõe que a instituição deve "Ter a iniciativa da informação e não deixar que a mídia o faça" 
Revista Científica do Corpo de Bombeiros Militar de Pernambuco

Artigo Publicado no Vol.05 N.13 - Edição Jul a Dez 2019 - ISSN 2359-4829

Versão on-line disponível em: http://www.revistaflammae.com

e ainda que "a imprensa e as novas mídias têm o poder de agravar a crise. Saber, portanto, administrar esses meios ameniza os problemas".

Definir quem falará pela instituição no momento da crise é uma decisão importante, pois o porta-voz deve dominar a informação a ser transmitida e ter segurança na sua verbalização. Sobre isso, Forni (2007, p.211) traz o preceito de que se deve "escolher um porta voz qualificado, não necessariamente $o$ principal executivo".

Nas comunicações da instituição deve-se contemplar todos os públicos sem distinção dando atenção a todos e comunicando o que for necessário para a compreensão do conteúdo do pronunciamento, bem como manter um canal aberto para que os diversos públicos possam se pronunciar. Para Rodrigues (2017, p.262) é importante que canais de comunicação estejam sempre à disposição do público para que ele possa se expressar, tais como ouvidorias, caixa de sugestão, pesquisa de satisfação, entre outros. Para Melo (2007, p.128) esse canal dá a possibilidade de ouvir e trabalhar o sentimento do público.Quanto ao preceito proposto por Forni (2007, p.211) o autor escreve que deve-se "Gerenciar a informação para todos os públicos, principalmente 0 interno" (FORNI, 2007, p.211).

A sobriedade e comprometimento da instituição no momento da crise devem ser mostrados a todo o tempo incansavelmente a fim de que não fiquem brechas para entendimentos errados e não se dê margem para haver pressão dos públicos e da imprensa. Sobre isso admite-se a premissa de que "não se deve ficar refém da imprensa, por pior que seja a situação" (FORNI, 2007, p.211).

Por fim, ao realizar os pronunciamentos em tempo de crise a instituição deve buscar estar próxima do público, tanto no respeito devido aos envolvidos, quanto na linguagem empregada para cada fim. Para Melo (2007, p.128) a comunicação deve ser clara e compassiva demonstrando preocupação com a resolução dos problemas. "Assumir a crise como um acontecimento lamentável, mas fortuito, para a empresa" e "Demonstrar que a disposição da 
organização ou do governo é corrigir o que deu errado" são preceitos também estabelecidos (FORNI, 2007, p.211).

\section{CONSIDERAÇÕES FINAIS}

De acordo com o conteúdo exposto por este trabalho, de fato, a crise é uma ameaça real a bens intangíveis de uma instituição pública, podendo implicar na ruptura de sua existência. É necessário indubitavelmente, a fim de que se enfrente de forma organizada a crise, entender o que é uma crise e o que representa para a instituição. Munido desse conhecimento fica claro que a preparação da instituição como prevenção a uma crise, com cultura estabelecida acerca da formação do gabinete de crise e do papel do assessor de comunicação, é uma ferramenta essencial para o êxito no enfrentamento da crise e para que a instituição prevaleça sobre o momento adverso.

Neste trabalho foi possível perceber a importância do assessor de comunicação para esse processo de gerenciamento do problema. Identificouse o assessor de comunicação como indispensável para composição de um comitê de crise, podendo agir como porta-voz da instituição e realizar o tratamento de toda a informação gerada numa crise a fim de que se estabeleça um canal de comunicação efetivo entre a instituição e seus públicos. Ainda foi possível estabelecer limites para a sua atuação, mostrando que o trabalho integrado dos membros do gabinete de crise apresenta resultados mais favoráveis para a instituição, representando uma forma de trabalho que respeita as competências de cada profissional envolvido na resolução da crise.

Por fim, foi possível definir procedimentos gerais aplicáveis nas crises, identificados como preceitos básicos norteadores, que alertam para prioridades e ações que devem ser evitadas a fim de que a comunicação entre a instituição e seus públicos ocorra de maneira respeitosa, compreensível e comprometida. Essa comunicação é capaz de preservar imagem e reputação da instituição sendo facilitada pelo trabalho prévio de aproximação com imprensa através do 
Revista Científica do Corpo de Bombeiros Militar de Pernambuco

Artigo Publicado no Vol.05 N.13 - Edição Jul a Dez 2019 - ISSN 2359-4829

Versão on-line disponível em: http://www.revistaflammae.com

fortalecimento dessa relação pelo setor de relações públicas ou comunicação deste órgão.

\section{REFERÊNCIAS}

ABRAPP. Manual de gestão de crise e imagem.edição única . São Paulo, SP,2015, p.14-15.

ALVES, José Eduardo Prestes. Comunicação de risco, elemento-chave na gestão de crises corporativas e um desafio para o século XXI: a teoria na prática, situação atual e tendências. Organicom, São Paulo, v. 4, n. 6, p. 8699, june 2007. ISSN 2238-2593. Disponível em: $<$ https://www.revistas.usp.br/organicom/article/view/138927>. Acesso em: 03 aug. 2018.2 doi:http://dx.doi.org/10.11606/issn.22382593.organicom.2007.138927.

ARRIBAS, Amaya. A gestão das relações públicas internacionais na crise da Volkswagen. Organicom, São Paulo, v. 13, n. 24, p. 174-188, june 2016. ISSN 2238-2593.

Disponível

em: $<$ https://www.revistas.usp.br/organicom/article/view/139327/134668>. Acesso em: 03 aug. 2018. doi:http://dx.doi.org/10.11606/issn.22382593.organicom.2016.139327.

BATISTA, Leandro Leonardo. A comunicação de riscos no mundo corporativo e o conteúdo da mensagem. Organicom, São Paulo, v. 4, n. 6, p. 100-113, june 2007. ISSN 2238-2593. Disponível em: $<$ https://www.revistas.usp.br/organicom/article/view/138928/134276>. Acesso em: 03 aug. 2018. doi:http://dx.doi.org/10.11606/issn.22382593.organicom.2007.138928.

BUENO, Wilson da Costa. A personalização dos contatos com a mídia e a construção da imagem das organizações.Organicom, São Paulo, v. 2, n. 2, p. 10-27, june 2005. ISSN 2238-2593. Disponível em: $<$ https://www.revistas.usp.br/organicom/article/view/138879/134227>. Acesso em: 03 aug. 2018. doi:http://dx.doi.org/10.11606/issn.22382593.organicom.2005.138879.

CARNIELLI, FiorenzaZandonade. Instituições e interesse público: os processos de comunicação pública como estratégia instituinte. Organicom, São Paulo, v. 14, n. 26, p. 64-75, sep. 2017. ISSN 2238-2593. Disponível em: $<$ https://www.revistas.usp.br/organicom/article/view/139357/134698>. Acesso em: 03 aug. 2018. doi:http://dx.doi.org/10.11606/issn.22382593.organicom.2017.139357. 
Revista Científica do Corpo de Bombeiros Militar de Pernambuco

Artigo Publicado no Vol.05 N.13 - Edição Jul a Dez 2019 - ISSN 2359-4829

Versão on-line disponível em: http://www.revistaflammae.com

FEDERAÇÃO NACIONAL DOS JORNALISTAS, Manual de Imprensa: assessoria de comunicação. 4.ed. Revista e Ampliada. Brasília, DF. 2007. p.16.

em: $<$ https://www.unesp.br/Home/aci ses/manual de assessoria de imprensa.pdf >. Acessado em: 31 jan. 2018.

FORNI, João José. Comunicação em tempos de crise. Organicom, São Paulo, v. 4, n. 6, p. 198-211, june 2007. ISSN 2238-2593. Disponível em: $<$ https://www.revistas.usp.br/organicom/article/view/138934/134282>. Acesso em: 03 aug. 2018. doi:http://dx.doi.org/10.11606/issn.22382593.organicom.2007.138934.

GOLDENBERG, M. A arte de Pesquisar. Rio de Janeiro: Record, 1997.

HENRIQUES, Márcio Simeone. Aspectos críticos para a compreensão da lógica estratégica no relacionamento entre organizações e comunidades. Organicom, São Paulo, v. 14, n. 26, p. 32-40, sep. 2017. ISSN 2238-2593. Disponível em: $<$ https://www.revistas.usp.br/organicom/article/view/139354/134695>. Acesso em: 03 aug. 2018. doi:http://dx.doi.org/10.11606/issn.22382593.organicom.2017.139354.

LOPES, Valéria de Siqueira Castro. O relações - públicas como gestor da imagem e a importância da mensuração dos resultados em ComunicaçãoCorporativa.

Organicom, São Paulo, v. 2, n. 2, p. 70-95, june 2005. ISSN 2238-2593. Disponível

em: $<$ https://www.revistas.usp.br/organicom/article/view/138882/134230>. Acesso em: 03 aug. 2018. doi:http://dx.doi.org/10.11606/issn.22382593.organicom.2005.138882.

MELO, Waltemir. Comunicação de risco: ação obrigatória das organizações que trabalham com produtos perigosos. Organicom, São Paulo, v. 4, n. 6, p. 114-135, june 2007. ISSN 2238-2593. Disponível em: $<$ https://www.revistas.usp.br/organicom/article/view/138929/134277>. Acesso em: 03 aug. 2018. doi:http://dx.doi.org/10.11606/issn.22382593.organicom.2007.138929.

MINAYO, M. C. S. (Org.). Pesquisa social: teoria, método e criatividade. Petrópolis: Vozes, 2001.

OLIVEIRA, Mateus Furlanetto de. O papel essencial das Relações Públicas no gerenciamento de crises. Organicom, São Paulo, v. 4, n. 6, p. 160-173, june 2007. ISSN 2238-2593. Disponível em: $<$ https://www.revistas.usp.br/organicom/article/view/138932/134280>. Acesso 
Revista Científica do Corpo de Bombeiros Militar de Pernambuco

Artigo Publicado no Vol.05 N.13 - Edição Jul a Dez 2019 - ISSN 2359-4829

Versão on-line disponível em: http://www.revistaflammae.com

em: $\quad 03$ aug. 2018. doi:http://dx.doi.org/10.11606/issn.22382593.organicom.2007.138932.

OLIVEIRA, Paulo Roberto Nassar de. O profissional de Relações Públicas no ambiente corporativo global.Organicom, São Paulo, v. 7, n. 13, p. 26-32, dec. 2010. ISSN 2238-2593. Disponível em: $<$ https://www.revistas.usp.br/organicom/article/view/139067/134416>. Acesso em: 03 aug. 2018. doi:http://dx.doi.org/10.11606/issn.22382593.organicom.2010.139067.

RODRIGUES, Maria Aparecida da Silva; RIOS, Izabel Cristina. Considerações sobre gestão da humanização hospitalar: o caso do Hospital Universitário da Universidade de São Paulo. Organicom, São Paulo, v. 14, n. 26, p. 257-271, sep. 2017. ISSN 2238-2593. Disponível em: $<$ https://www.revistas.usp.br/organicom/article/view/139372/134713>. Acesso em: 03 aug. 2018. doi:http://dx.doi.org/10.11606/issn.22382593.organicom.2017.139372.

SANTOS, Lucivânia Pereira dos; SANTOS, Maria da ConceiçãoDias Gouveia dos; NETO, Wilson Rodrigues de Melo; ANDRADE, Polyana Bittencourt. A Assessoria de Imprensa na Administração Pública: Uma Análise do Hospital de Urgência do Estado de Sergipe. In: Congresso Brasileiro de Ciências da Comunicação, 33., 2010, Caxias do Sul, Anais do XXXIII Congresso Brasileiro de Ciências da Comunicação, 02 a 06 setembro. 2010. Caxias do Sul: INTERCOM - Sociedade Brasileira de Estudos Interdisciplinares da Comunicação, 2010.2 Disponível em: $<$ http://www.intercom.org.br/papers/nacionais/2010/resumos/R5-3037-1.pdf>. Acessado em: 31 jan. 2018.

SHINYASHIKI, Roberto Tadeu; FISCHER, Rosa Maria; SHINYASHIKI, Gilberto. A importância de um sistema integrado de ações na gestão de crises. Organicom, São Paulo, v. 4, n. 6, p. 148-159, june 2007. ISSN 22382593.

em: $<$ https://www.revistas.usp.br/organicom/article/view/138931/134279>. Acesso em: 03 aug. 2018. doi:http://dx.doi.org/10.11606/issn.22382593.organicom.2007.138931.

TAVARES, Ailanda Ferreira; SANTOS, Adriana C. Omena dos. Comunicação pública, tecnologias e assessorias de imprensa no âmbito público. In: Congresso Brasileiro de Ciências da Comunicação, 38., 2015, Rio de Janeiro, Anais do XXXVIII Congresso Brasileiro de Ciências da Comunicação, 04 a 07 setembro. 2015. Rio de Janeiro: INTERCOM - Sociedade Brasileira de Estudos Interdisciplinares da Comunicação, 2015. Disponível em: $<$ http://portalintercom.org.br/anais/nacional2015/resumos/R10-0154-1.pdf>. Acessado em: 31 jan. 2018. 